\title{
Consumer Awareness and Usage of Nutrition Information in Botswana
}

\author{
Godfrey Themba (Corresponding author) \\ Department of Marketing, University of Botswana \\ Private Bag UB 00701, Gaborone, Botswana \\ E-mail: Themba@mopipi.ub.bw
}

Joyce Tanjo

Local Enterprise Authority (LEA), Private Bag 00321, Gaborone, Botswana

E-mail: Tanjo.joyce@yahoo.com

Received: February 25, 2013 Accepted: March 15, 2013 Published: March 19, 2013

doi:10.5296/bmh.v1i1.3401ＵRL: http://dx.doi.org/10.5296/bmh.v1i1.3401

\begin{abstract}
Nutrition information enables consumers to make informed decisions when purchasing and consuming food products. Despite this, the issue of consumer awareness and usage of nutrition information has attracted little research attention in developing countries. This study presents findings of an empirical investigation of nutrition information awareness and usage in Botswana. The study is descriptive and data was collected using a structured questionnaire administered to a sample of 150 consumers in Gaborone, the Capital City of Botswana. A mall-intercept technique was used in the selection of the respondents. The main findings of the study indicate that the level of awareness of nutrition information among the sampled consumers is relatively high, and that the majority of them use nutrition information to inform food purchases. The study further finds that whereas nutrition information awareness does not significantly differ across the demographic segments, usage differs. Lack of knowledge and interest are the main factors that prevent consumers from using nutrition information. Nutrition information is mostly used when comparing products or when buying food products for the first time. These findings highlight the need to improve nutrition education in Botswana. The findings also suggest that food producers in Botswana need to use nutrition information to differentiate their products from competitors'. Similarly, the findings highlight the need for the food industry in Botswana to establish more effective nutrition information labeling standards. However, these findings need to be interpreted with caution as they are based on consumers' self-report of nutrition information use, which is highly subjective.
\end{abstract}

Keywords: food labelling, consumer behaviour, nutrition information, Botswana 


\section{Introduction}

Public interest in healthy eating has increased over the years (Grunert and Wills, 2007). According to Shine et al., (1997), increased interest in nutritional issues in recent years has been fuelled by a number of factors including lifestyle, ageing population, dietary and safety concerns. As consumers have become increasingly concerned about what they eat and how it affects their health, the food industry has responded by providing more detailed nutrition information on their food labels (Petrovici et al. 2012).

Despite the growth in demand for and supply of nutritional information in recent years relatively little empirical research has been conducted in developing countries to determine the extent to which consumers know and actually use such information to inform their purchases. Most of the accumulated knowledge on nutritional information use is largely based on studies conducted in developed countries and in particular the UK and USA (European Heart Network, 2003). In Botswana, to the best of our knowledge, no such study has been reported to date. This paucity of research in Botswana raises the following important questions:

1) Just how aware Batswana are of nutrition information on food products? Does awareness of nutrition information vary across demographic segments of the population?

2) How do consumers in Botswana use nutrition information on food products? For what purpose and to what extent do consumers in Botswana use nutrition information? Does usage of nutrition information vary across demographic segments of the population? Under what situations do consumers use nutritional information? What are the main reasons for reading and for not reading nutrition information on food products?

The present study is designed to address the above questions which relates to consumer awareness and usage of nutrition information in Botswana. The study is descriptive and seeks to provide further insights into consumer awareness and usage of nutrition information in Botswana.

The paper is divided as follows: after introduction follows literature review and hypotheses. We then present the methodology and the findings. Discussions of key findings, conclusions and managerial implications follow. Finally, we present limitations of the study and directions for future research.

\section{Literature Review \& Hypotheses}

\subsection{Nutritional Information Use}

In the age when more than ever before consumers are constantly being reminded by health officials of the connection between nutrition and good health it is surprising that most studies report relatively low usage of nutritional information on food products. In a study of French consumers' use of nutritional information Mannell et al. (2006) found that the majority of the respondents do not read nutrition labels because of lack of interest. After an exhaustive review of European studies Higginson et al. (2002) observed that studies of nutrition label 
use reveal generally low levels of use of the information. They cite studies which indicate that in the UK although 62 percent of consumers are aware of nutrition labels only 22 to 59 percent of adults look for information on nutrition when shopping. In an earlier study Meiden and Edris (1990) as cited by Siu and Tsoi (1998p.25) revealed that the use of nutrition information by UK consumers is notably low. Similarly, Ranilovic and Baric (2011), reported in their study of Croatian consumers that 36 percent of the subjects had never read nutrition labels during the last 12 months whilst 24.8 percent claimed they rarely read nutrition labels. In Malawi Kasapila and Shawa (2011) found that only 29.1 percent used the information. However, in Lesotho a country that has a lot in common with Botswana including for example, the same language and culture, Mahgoub et al. (2007) found that 63 percent of the respondents used nutritional information.

Studies have also shown that consumers use nutritional information for a variety of reasons (e.g. Higginson et al. 2002). Freckleton (1986) as cited by Higginson et al. (2002) found that the most common use of nutritional information is to compare nutrition profiles between two different makes of the same product. Other common uses indicated in this study include finding out how the product fits in with the rest of the diet or meal. Higginson et al. (2002) also found that product comparison to choose healthy products was the most common form of nutrition label use, followed by making judgments of the amount of a nutrient in a product to assist in purchase decision making. Ranilovic and Baric (2011) found that in Croatia, "curiosity", "wish for healthy eating" and "having had nutrition counseling” were the most important reasons for reading nutrition labels on food products. Other important reasons mentioned include product comparisons, family habits and special diets. In a study conducted in Ireland Shine et al. (1997) observed that consumers used nutritional information in order to know more about the food they are about to purchase and to establish nutritional content of specific foods products. They also observed that avoidance of negative nutrients as a reason for reading nutritional labels was apparent throughout the results of their study.

According to Higginson et al., 2002, accumulated knowledge on nutrition usage is largely based on consumers' self-reports. Grunert and Wills (2007) have criticized the self-reported use of nutritional information, arguing that although self-reported use of nutrition is high, actual use is considerably low. Another criticism relates to the fact that although the terms "reading" and "using" are conceptually different (reading does not automatically translate into using) they are often used interchangeably by researchers. After an exhaustive review of European studies Cowburn, G. and Stockley (2005), as cited by Grunert and Wills (2007p.386) concluded that although reported use of nutrition labels is high, actual use is considerably lower.

\subsection{Determinants of Nutritional Information Use}

There has been considerable empirical research focused on the determinants of nutritional and health information use (Drichoutis et al. 2006). Available empirical evidence indicates that a wide range of factors determine nutrition and health information use (Petrovici et al. (2012). For example, in a study of supermarket shoppers in the South East of England Petrovici et al. (2012), found that health related factors (e.g. health status); the level of 
product involvement (e.g. importance attached to price); the situational, behavioral \& attitudinal factors (e.g. ability to comprehend labels) and individual characteristics (e.g. age) influenced usage of nutrition information and health claims on food products. Demographic differences regarding nutritional information use have been widely noted in literature (e.g. Wiles et al. 2009; Ranilovic and Baric (2011). Mahgoub et al. (2007) found that age, educational level and family income significantly influenced nutrition information use in Lesotho. Kasapila and Shawa (2011) found that women were more likely to consult nutrition labels when purchasing food products than men. They also observed differences in usage between urban and rural consumers with the former being more inclined to read nutrition information than the latter. According to them, income and educational level disparities between urban and rural consumers accounted for the observed usage differences. Ranilovic and Baric (2011) found that in Croatia females, the highest educated participants, those still undergoing education, the physically active, and those on a special diet were more likely to use nutrition information when purchasing food. Mannell et al. (2006) found that French consumers who are most likely to use nutritional information are those on special diet $(\mathrm{p}=.0004)$, women $(\mathrm{p}=.0000)$, and those older than 40 years old $(\mathrm{p}=.0151)$. Siu and Tsoi (1998), in their investigation of nutritional label usage among Chinese consumers found that frequent users are in the age group 35-54. Following their review of European studies Grunert and Wills (2007) noted that a range of demographic effects have been reported, including higher self-reported label use by women, older consumers, more educated consumers and by consumers in the higher social strata.

\subsection{Effects of Nutritional Information Use on Consumer Behavior}

Schiffman and Kanuk (2007 p.3) define consumer behavior as "the behavior that consumers display when searching for, purchasing, evaluating and disposing of products and services that they expect will satisfy their needs”. This includes decisions which consumers make such as what to buy, when to buy it, where to buy it, how to buy it and how to use it. The extant literature on consumer behavior indicates that a myriad of factors influence consumers when purchasing goods and services (e.g. Paterson et al. 2009). According to Drichoutis et al. (2006), there is empirical evidence indicating that consumer purchase behavior is affected by nutritional information and health claims on food products. Indeed, marketers frequently use health claims and nutritional information to encourage brand switching (Drichoutis et al. (2006). Drichoutis et al. (2006) also observed that nutritional information affected purchasing behavior mainly because consumers want to avoid the negative nutrients in food products and because nutritional information influences consumer evaluations and perceptions of the product. Mahgoub et al. (2007) found that in Lesotho 63\% claimed that they use nutritional information when shopping which suggest that consumers selected food products based on their nutritional content. In their study in South Africa Wiles et al. (2009) concluded that nutritional information influence the purchase of selected foods.

\subsection{Syntheses \& Hypotheses}

The extant literature reviewed indicate that much research on nutrition information use, its determinants and effects on consumer purchase behavior has been conducted in recent years. 
The extant literature also shows that most of this research has been concentrated in developed countries especially the UK and USA. Few studies have been conducted in developing countries and Africa in particular. This study therefore seeks to address this paucity of research in developing countries and Africa in particular by focusing on Botswana.

Based on the literature reviewed and the researcher's personal insights, the following hypotheses relating to nutrition information awareness and usage in Botswana are proposed:

H1: Awareness of nutrition information on food products varies according to the demographic characteristics of consumers.

H2: Usage of nutrition information varies according to the demographic characteristics of consumers.

\section{Methodology}

A descriptive research design was deemed suitable as the study seeks to describe the level of awareness, and usage of nutrition information in Botswana. A convenience sample was selected using the mall-intercept technique which has been widely used and recommended in literature (Subramaniam and Marimuthu, 2010). This method is also considered to be free of systematic bias and that it gives respondents a sense of anonymity (Khare et. al. 2012). To obtain a more representative sample, consumers where randomly selected from fixed locations at the main shopping centers in Gaborone, the capital city of Botswana. Prior consent to administer the questionnaires was obtained from management of the shopping centers. According to Shine et al., (1997), selecting respondents at fixed locations in major shopping malls is recommended as nutrition information is provided on food products purchased in food retail outlets.

In line with previous studies, data was collected using a structured questionnaire which sought information regarding the respondent's background, awareness and usage of nutrition information on food packages. The questionnaires were completed in the presence of the researcher who provided assistance when needed. The questionnaire was piloted to identify and eliminate potential problems (Malhotra, 2009). In total 150 usable questionnaires were obtained. All the questionnaires were coded and entered into the computer for analysis using SPSS statistical software (Version 15.0, 2008; SPSS Inc, Chicago, IL, USA)

Data analysis was carried out in three stages. In the first stage data cleaning was performed using SPSS in order to rid the data of spurious responses. Secondly, data was analyzed using descriptive statistics to reveal underlying patterns. Thirdly chi-square analyses were carried out to investigate relationships amongst the variables and to test the hypotheses

\section{Results}

\subsection{Profile of the Respondents}

The majority of the respondents were female (59 percent), the youth (57 percent), holders of a degree \& above (59 percent), employed (62 percent), large family size (83 percent), high income (55 percent), and no special dietary needs (63 percent). The results of the survey also 
indicate that 78 percent of the respondents demonstrated a high level of awareness of nutritional information on food products. Those who claim that they read nutritional information when purchasing food products were in the majority (88 percent) whilst 12 percent never read nutritional information. The demographic profile of consumers surveyed is reflected in table 1 below.

Table 1. Profile of the respondents $((n=150)$

\begin{tabular}{|c|c|c|}
\hline \multirow{2}{*}{ Demographic characteristics: } & Frequency & Percent \\
\hline & 62 & 41 \\
\hline $\begin{array}{ll}\text { Gender: } & \text { Male } \\
& \text { Female }\end{array}$ & 88 & 59 \\
\hline \multirow{2}{*}{$\begin{array}{ll}\text { Age: } & \text { Youth(below 35) } \\
& \text { Adult (36 and above) }\end{array}$} & 86 & 57 \\
\hline & 64 & 43 \\
\hline \multirow{2}{*}{$\begin{aligned} \text { Educational Level: Low (Up to Diploma) } \\
\text { High (Degree \& above) }\end{aligned}$} & 62 & 41 \\
\hline & 88 & 59 \\
\hline \multirow{2}{*}{$\begin{array}{ll}\text { Employment Status: } & \text { Employed } \\
& \text { Unemployed }\end{array}$} & 93 & 62 \\
\hline & 52 & 38 \\
\hline \multirow{2}{*}{$\begin{array}{ll}\text { Household Size: } & \text { Small (1-4 members) } \\
& \text { Large (5 and above) }\end{array}$} & 26 & 17 \\
\hline & 124 & 83 \\
\hline \multirow{2}{*}{$\begin{array}{r}\text { Household Monthly Income: Low (Up to BWP10, 000) } \\
\text { High (Above BWP10, 000) }\end{array}$} & 67 & 45 \\
\hline & 83 & 55 \\
\hline \multirow{2}{*}{$\begin{array}{ll}\text { Special Dietary needs: } & \text { Yes } \\
& \text { No }\end{array}$} & 56 & 37 \\
\hline & 94 & 63 \\
\hline \multirow[t]{3}{*}{ Awareness of nutritional information: } & 117 & 78 \\
\hline & 33 & 28 \\
\hline & 132 & 88 \\
\hline Do not read nutrition labels & 18 & 12 \\
\hline
\end{tabular}

\subsection{Demographic Characteristics by Awareness of Nutritional Information on Food Products}

We postulated in this study that awareness of nutritional information on food products in Botswana varies according to demographic characteristics of consumers. The results of cross tabulation indicate that those most likely to be aware of nutritional information on food products are in the categories high income, high education, employed, no special dietary needs, youth, female, and large family. Similarly the results indicate that those most likely to be unaware are in the categories high income earners, high education, no special dietary needs, youth, female and large family size. It is apparent from these findings that awareness of nutrition information does not differ according to demographic characteristics of consumers. With the exception of the findings relating to family size (Chi-square 7.559, $\mathrm{p}=0.006,1 \mathrm{df}$ ) all the other findings do not show statistical significance at the 0.01 and 0.05 levels which suggest that H1is not generally supported. However, since these results do not show statistical significance they need to be treated with a high degree of caution. These results are reflected in table 2 below. 
Table 2. Cross tabulation of demographic characteristics of consumers by nutritional information awareness

\begin{tabular}{|c|c|c|c|c|}
\hline \multirow[t]{2}{*}{ Demographic Variable } & \multicolumn{2}{|c|}{$\begin{array}{l}\text { Number }(\%) \text { of respondents } \\
\text { who are aware or unaware } \\
\text { of nutrition information on } \\
\text { food products: }\end{array}$} & \multirow[t]{2}{*}{ Chi-square } & \multirow[t]{2}{*}{ P-value } \\
\hline & Aware & Unaware & & \\
\hline \multirow{2}{*}{$\begin{array}{r}\text { Income: Low (Up to P10 000) } \\
\text { High ( Above P10 000) }\end{array}$} & $52(44.4 \%)$ & $15(45.5 \%)$ & \multirow[t]{2}{*}{$0.011(1 d . f)$} & \multirow[t]{2}{*}{0.918} \\
\hline & $65(55.6 \%)$ & $18(54.5 \%)$ & & \\
\hline \multirow{2}{*}{$\begin{array}{r}\text { Education: Low (Up to diploma) } \\
\text { High (Degree \& above) }\end{array}$} & $52(44.4 \%)$ & $10(30.3 \%)$ & \multirow[t]{2}{*}{ 2.123(1d.f) } & \multirow[t]{2}{*}{0.145} \\
\hline & $65(55.6 \%)$ & $23(69.7 \%)$ & & \\
\hline \multirow{2}{*}{$\begin{array}{c}\text { Employment status: Employed } \\
\text { Unemployed }\end{array}$} & 69 (59\%) & $24(72.7 \%)$ & \multirow[t]{2}{*}{ 2.066(1d.f) } & \multirow[t]{2}{*}{0.151} \\
\hline & $48(41 \%)$ & $9(27.3 \%)$ & & \\
\hline \multirow{2}{*}{$\begin{array}{r}\text { Special dietary needs: Yes } \\
\text { No }\end{array}$} & 42 (35.9\%) & $14(42.4 \%)$ & \multirow[t]{2}{*}{$0.469(1 d . f)$} & \multirow[t]{2}{*}{0.494} \\
\hline & 75 (64.1\%) & $19(57.6 \%)$ & & \\
\hline \multirow{2}{*}{$\begin{aligned} \text { Age : } & \text { Youth (Below } 35 \text { years) } \\
& \text { Adult (Above } 35 \text { years) }\end{aligned}$} & $67(57.3 \%)$ & $19(57.6 \%)$ & \multirow[t]{2}{*}{0.001 (1d.f) } & \multirow[t]{2}{*}{0.975} \\
\hline & $50(42.7 \%)$ & $14(42.4 \%)$ & & \\
\hline \multirow[t]{2}{*}{ Gender: } & $52(44.4 \%)$ & $10(30.3 \%)$ & \multirow[t]{2}{*}{ 2.123(1d.f) } & \multirow[t]{2}{*}{0.145} \\
\hline & $65(55.6 \%)$ & 23 (69.7\%) & & \\
\hline \multirow{2}{*}{$\begin{array}{l}\text { Household size: Small (1-4) } \\
\text { Large (5 or more) }\end{array}$} & $11(33.3 \%)$ & $15(12.8 \%)$ & \multirow[t]{2}{*}{ 7.559(1d.f) } & \multirow[t]{2}{*}{$0.006 * *$} \\
\hline & $22(66.7 \%)$ & 102 (87.2\%) & & \\
\hline
\end{tabular}

** Significant at .01 level

\subsection{Demographic Characteristics of Consumers by Nutritional Information Usage}

We also postulated in this study that usage of nutritional information varies according to demographic characteristics of consumers. The results of cross tabulation (Table 3) indicates that those who do not use nutrition information on food products to inform their purchases are more likely to be in the group categories of low income, low education, unemployed, youth and male. Similarly, those who use the information are more likely to be in the group categories of high income, high education, employed, adult, and female. Based on these findings it appears that usage of nutritional information in Botswana does vary according to demographic characteristics of users thus confirming H2. Furthermore the results relating to income (Chi-square 4, $\mathrm{p}=0.045$, df1) and employment status (Chi-square 4.6, $\mathrm{p}=0.03,1 \mathrm{df}$ ) show statistical significance at the 0.05 level which implies that we can place a higher level of confidence on these findings. 
Table 3. Cross tabulation of demographic characteristics by nutrition information use

\begin{tabular}{|c|c|c|c|c|}
\hline \multirow[t]{2}{*}{ Demographic Variable } & \multicolumn{2}{|c|}{$\begin{array}{l}\text { Number (\%) r of } \\
\text { respondents who "Do Not } \\
\text { Read" or "Read" nutrition } \\
\text { information on food } \\
\text { products: }\end{array}$} & \multirow[t]{2}{*}{ Chi-square } & \multirow[t]{2}{*}{ P-value } \\
\hline & Do Not Read & Read & & \\
\hline $\begin{aligned} \text { Income : Low (Up to P10 000) } \\
\text { High (Above P10 000) }\end{aligned}$ & $\begin{array}{l}12(66.7 \%) \\
6 \quad(33.3 \%)\end{array}$ & $\begin{array}{l}55(41.7 \%) \\
77(58.3 \%)\end{array}$ & 4.006 (1d.f) & $0.045^{*}$ \\
\hline $\begin{array}{r}\text { Education: Low (Up to diploma) } \\
\text { High (Degree \&above) }\end{array}$ & $\begin{array}{l}11(61.1 \%) \\
7 \quad(38.9 \%)\end{array}$ & $\begin{array}{l}51(38.6 \%) \\
81(61.4 \%)\end{array}$ & 3.300 (1d.f) & 0.069 \\
\hline $\begin{array}{l}\text { Employment status: Employed } \\
\text { Unemployed }\end{array}$ & $\begin{array}{l}7 \quad(38.9 \%) \\
11(61.1 \%)\end{array}$ & $\begin{array}{l}86(65.2 \%) \\
46(34.8 \%)\end{array}$ & 4.637 (1d.f) & $0.031^{*}$ \\
\hline $\begin{array}{l}\text { Youth (below 35) } \\
\text { Adult (above 35) }\end{array}$ & $\begin{array}{l}13(72.2 \%) \\
5(27.8 \%)\end{array}$ & $\begin{array}{l}73(55.3 \%) \\
59(44.7 \%)\end{array}$ & 1.854 (1d.f) & 0.173 \\
\hline $\begin{array}{l}\text { Male } \\
\text { Female }\end{array}$ & $\begin{array}{l}10(55.6 \%) \\
8(44.4 \%)\end{array}$ & $\begin{array}{l}52(39.4 \%) \\
80(60.6 \%)\end{array}$ & 1.706 (1d.f) & 0.191 \\
\hline
\end{tabular}

Note: Cross tabulations of special dietary needs and household size by usage were not included due to low expected frequency counts (Bryman and Cramer, 2005). *Significant at .05 level.

\subsection{Situations under Which Nutrition Information Is Used}

When asked to indicate the situations under which they used nutrition information to inform their purchases, 57 percent indicated using nutrition information when purchasing a product for the first time and 53 percent indicated that they use the information when comparing food products. Similarly, 48 percent said they use the information when trying to lose weight whilst 45 percent use it when following a special diet. 37 percent use nutrition information when buying certain foods and 1 percent used it in "other" situations. This information is reflected in table 4 below.

Table 4. Situations under which nutrition information is used $(n=150)$

\begin{tabular}{ll}
\hline Situations: & Percent \\
\hline When purchasing a product for the first time & 57 \\
When trying to lose weight & 48 \\
When following a special diet & 45 \\
When comparing food products & 53 \\
When buying certain foods & 37 \\
Other & 1 \\
\hline
\end{tabular}

\subsection{Reasons for Reading Nutritional Information}

The reasons for reading nutrition information were also explored. The respondents were asked to rank on a scale ranging from 1 (most important) to 5 (least important), the reasons 


\section{Macrothink Institute ${ }^{\text {TM }}$}

for reading nutrition information. Product comparison was ranked highest by 29 percent of the respondents. This was followed by curiosity (34 percent), advice from nutrition counseling (25 percent), family member habits (30 percent) and special dietary needs (57 percent) in that order. The responses are reflected in table 5 below:

Table 5. Reasons for reading nutrition information $(n=150)$

\begin{tabular}{lll}
\hline $\begin{array}{l}\text { Reasons for reading nutrition information on food } \\
\text { packages }\end{array}$ & Rank & Percent \\
\hline Product comparisons & 1 & 29 \\
Curiosity & 2 & 34 \\
Advice from nutrition counseling & 3 & 25 \\
Family member habits & 4 & 30 \\
Special dietary needs & 5 & 57 \\
\hline
\end{tabular}

\subsection{Reasons for Not Reading Nutrition Information}

The respondents were further asked to rank the reasons for not reading nutrition information in order of applicability to them with 1 being the most applicable. According to the results of this study (Table 5) "Lack of nutrition knowledge" was ranked highest (1) by 56 percent of the respondents, followed by "Lack of interest" (2) and "Do not generally believe nutrition information on food products" (3) ranked by 25 and 23 percent of the respondents respectively. These were followed by "Food labels use small prints which are difficult to read" (23 percent), "Read nutrition information only when purchasing food items for the first time” (22 percent) and “Time pressures” (21 per cent) in that order.

Table 6. Reasons for not reading nutrition information $(\mathrm{n}=150)$

\begin{tabular}{lll}
\hline $\begin{array}{l}\text { Reasons for not reading nutrition information on food } \\
\text { packages }\end{array}$ & Rank & Percent \\
\hline Lack of nutrition knowledge & 1 & 56 \\
Lack of interest & 2 & 25 \\
Do not generally believe nutrition information on food labels & 3 & 19 \\
Food labels use small prints which are difficult to read & 4 & 23 \\
Read nutrition labels only when purchasing food items for the & 5 & 22 \\
first time & & \\
Time pressures & 6 & 21 \\
\hline
\end{tabular}

\section{Discussion}

\subsection{Nutrition Information Awareness and Usage}

The results of the present study indicate that an overwhelming majority (78 percent) of the respondents are aware of nutrition information on food products. Similarly, the study indicates that those who claim to use the information to inform purchases are also in the 
majority (88 percent). This result suggests that those who use nutrition information are more than those who are aware of such information. This rather strange finding suggests that the respondents may have confused usage with awareness when completing the questionnaire. Nonetheless these findings somehow parallel those of the study conducted in Lesotho by Mahgoub et al. (2007) where it was found that 63.8 percent claimed that they use nutrition information when shopping. However, these findings contrast those of Kasapila and Shawa (2011) who found that in Malawi only 29.1 percent use nutrition information and that 73.8 percent do not understand nutrition information which suggests a much lower usage. The issue of consumer understanding of nutrition information is important because unless consumers understand such information they cannot effectively use it to inform their purchases (Drichoutis et al. 2006). Although we did not address this issue directly, studies elsewhere indicate that knowledge of nutrition information is positively related to use (Guthrie et al. 1995). Our findings also do not lend support to similar studies conducted in Europe. For example, Ranilovic and Baric (2011) found that among Croatian consumers the reading of nutrition labels does not play an important role during food purchase. In that study, a majority of the respondents (60.4 percent) claimed that they "never" or "rarely" read nutrition labels when purchasing food. According to Ranilovic and Baric (2011) similar results were reported in qualitative studies conducted in France, The United Kingdom, Germany and the Netherlands. It is worth noting however that the relatively high nutrition information use reflected in our study need to be considered with caution. As previous researchers have pointed out, self- reported use maybe higher than actual use (Higginson et al. 2002). Similarly nutrition label reading does not automatically translate into use (Higginson et al. 2002).

Our findings also indicate that awareness of nutrition information does not vary according to demographic characteristics of consumers. Specifically, the results indicate that those most likely to be aware of nutrition information are just as likely to be unaware. However, with exception of the findings relating to family size $(\mathrm{P}<.01)$ all the other findings do not show statistical significance which suggest that the results need to be treated with caution.

Consistent with previous studies our findings indicate that use of nutrition information during food purchases varies according to the demographic characteristics of consumers. Specifically, our findings indicate that those most likely to use nutrition information on food products are in the group categories of high income, high education, employed, youth and female. There is considerable empirical support for these findings. Shine et al. (1997a) found that those who read nutrition information tend to be female and have completed tertiary education. They also investigated the relationship between attitudes to nutrition and use of nutrition labeling and found a significant positive relationship. Wiles et al. (2009) found that in South Africa, those with tertiary education were more likely to use the nutrition information on the food label than those with secondary education. They further found that usage increased with the increase in the number of household members and the amount of money available for food purchase. (Wandel (1997) found that more women than men read nutrition labels. Guthrie et al. (1995) also found a marked increase in label usage as the number of household increased. Abbot found that females, the better educated and those with 
special dietary needs made relatively greater use of food label information. Mahgoub et al. (2007) found that in Lesotho the use of nutrition knowledge when purchasing food products increased with age, education level and family income. However, past studies also indicate inconsistences in findings. For example, in contrast to most studies Shine et al. (1997a) found that age, socio-economic status, marital status, children in the household had no effect on nutrition information use.

\subsection{Situations under Which Nutrition Information Is Used}

In this study we also investigated the situations under which consumers use nutrition information. Expectedly and in line with previous studies most consumers (57percent) claimed that they use nutrition information when purchasing a product for the first time. Similarly most of the respondents also claimed that they use nutrition information when comparing food products. A notable number also indicated that they used nutrition information when trying to lose weight (48 percent), when following a special diet and when buying certain food products (37 percent). These findings are both intuitive and consistent with previous findings. Due to the posited link between good health and food (Shine et al. 1997a; Abbott 1997) it makes sense that consumers read nutritional labels when purchasing food products for the first time or when comparing food products that they consider purchasing. Wandel (1997 p.213), observed that food labels were found particularly useful when buying mixed products, low fat products and products which could have a high fat content.

\subsection{Reasons for Reading Nutrition Information}

Our findings indicate that amongst the reasons for reading nutrition information product comparison is considered the most important reason followed by curiosity, advice from nutrition counseling, family member habits and special dietary needs in that order. Product comparison has also featured prominently in previous studies as the reason for using nutrition labels (Higginson et al. (2002). According to Higginson et al. (2002), "the most common procedure is to compare two or more products of the same type on the basis of a single nutrient, or across a range of nutrients." Surprisingly curiosity is ranked higher than advice from nutrition counseling and special dietary needs. Previous studies have shown that consumers who have a "special interest" in diet are more likely to read nutrition labels (e.g. Abbot, 1997). According to Wandel (1997), health considerations are the most decisive driving forces for reading the food labels. However, given that the majority of the respondents in this study do not have special dietary needs, health consideration would not be a driving force for reading nutrition labels to the majority of them.

\subsection{Reasons for Not Reading Nutrition Information}

According to the results of the present study, most of the respondents find lack of nutrition knowledge to be the main reason for not reading nutrition information. This finding makes intuitive sense. Unless consumers are knowledgeable with regard to nutrition they would not be able to understand nutrition labels. Moreover consumer interest in reading nutrition information is likely to be negatively affected by lack of nutrition knowledge. This explains 
why in this study lack of interest is found to be another important reason for not reading nutrition information. Several studies have found evidence supporting a positive relationship between label use and knowledge (e.g. Wiles et al., 2009; Guthrie et al. 1995). For example Wiles et al (2009) found that the respondents with a tertiary education were more likely to use the nutrition information than those with a secondary education, which suggest that nutrition knowledge is higher among those with tertiary education. According to Drichoutis et al. (2006p.6), "nutrition knowledge may facility label use by increasing its perceived benefits and by increasing the efficiency of label use, thereby decreasing the cost of using labels.” In their study Mahgoub et al. (2007) highlighted lack of education as one of the barriers to effective use of nutrition information. Nevertheless Drichoutis et al. (2006p.6), argue that although it is reasonable to expect that nutrition knowledge can affect nutritional label use, it is also possible that label use can affect nutrition knowledge. In their view, as consumers read more nutritional labels from the food they purchase, their knowledge of nutrition can improve. The other important reason for not reading nutrition labels identified in this study is that "food labels use small prints which are difficult to read". Shine et al. (1997b) also found that the respondents, particularly the older consumers, felt that the size of the print on nutrition labels is too small, thus making it difficult to read. In their study Ranilovic and Baric (2011p.119) concluded that "the small letter size poses a starting barrier to [older consumers]". In their view the format of the label has a notable impact on using nutrition information on food labels. Other respondents identified "Read nutrition labels only when purchasing food items for the first time" (22 percent), Time pressures (21percent) and "Do not generally believe nutrition information on food labels" (19 percent) as reasons for not reading nutrition information. Similar findings are also reflected in previous studies. Wandel (1997 p. 213), for example, observed that some informants said that even though they usually did not pay attention to the food labels, they made a point of reading them when they encountered new products. Drichoutis et al. (1998), as cited in Drichoutis et al. (2006) found that people with low levels of time pressure are more likely to use nutrition information. According to Drichoutis et al. (2006), time pressure limits the consumer's search for nutrition information.

\section{Conclusions and Implications}

The results of the present study suggest that the level of nutrition information awareness among consumers in Botswana is relatively high and that most consumers use such information to inform their purchases. The results also indicate that in Botswana nutrition information awareness does not significantly differ according to demographic characteristics of users thus suggesting that any one consumer group is just as likely to be aware or unaware of nutrition information on food products as any other group. On the other hand the results show that usage of nutrition information does vary according to demographic characteristics of consumers and this finding is consistent with previous studies. Typically those most likely to use nutrition information when purchasing food products are older highly educated females who are in well-paying jobs. The result further indicates that lack of knowledge is the main factor that prevents consumers from using nutrition information followed by lack of interest (which may be the result of lack of knowledge). The results also indicate that consumers 
mostly use nutrition information when comparing products and when buying food products for the first time.

The results of this study have both policy and managerial implications. The main policy implication is that the study highlights the need to improve nutrition education in Botswana. In the short-term, this requires the Ministry of Health to engage in public educational campaigns that emphasizes the importance of nutrition as part of healthy eating. For the long-term, the Ministry of Education need to ensure that nutrition education becomes an integral part of the curriculum right from the formative stages of education to secondary.

From a managerial perspective, the findings of this study indicate that food producers in Botswana need to use nutrition information to differentiate their products from competitors' as this can give them competitive advantage in the marketplace. Furthermore, the findings of this study indicate that food producers in Botswana should improve the quality of nutrition information labels on food packages to ensure that they are user friendly. More importantly, there is need for the food industry in Botswana to establish more effective nutrition information labeling standards.

\section{Limitations and Further Research}

The main limitations of this study are that a relatively small sample was used and that the findings are based on consumer self-report method which has been criticized by previous scholars. It is therefore recommended that future research should use a larger sample that reflects a cross section of the population of Botswana. In order to avoid the weaknesses inherent in the self-report methods, a verbal protocol analysis method, which has been recommended by previous researchers, could be employed in future studies.

\section{References}

Abbott, R. (1997). Food and Nutrition Information: a study of sources, uses, and understanding. British Food Journal, 99(2), 43-49.

Bryman, A., \& Cramer, D. (2005). Quantitative Data Analysis with SPSS 12 and 13. London and New York: Routledge.

Drichoutis, A. C., Lazaridis, P., \& Nayga, Jr. R. M. (2006). Consumers' Use of nutrition labels: A review of research studies and issues. Academy of Marketing Science Review, 2006(9), 1-22. Retrieved August 28, 2012 from http:www.amsreview.org/articles/drichoutis09-2006.pdf

European Heart Network. (2003). A systematic review of the research on consumer understanding of nutrition labeling. European Heart Network. Brussels.

Grunert, K. G., \& Wills, J. M. (2007). A review of European research on consumer response to nutrition information on food labels. Journal of Public Health, 15, 385-399. http://dx.doi.org/10.1007/s10389-007-0101-9

Guthrie, J. F., Cleveland, L. E., \& Welsh, S. (1995). Who uses nutritional labeling, and what effects does label use have on diet quality. Journal of Nutrition Education, 27(4), 163-172. 
Higginson, C. S., Kirk, T. R., Rayner, M. J., \& Draper, S. (2002). How do consumers use nutrition label information. Nutrition \& Food Science, 32(4), 145-152. http://dx.doi.org/10.1108/00346650210436253

Kasapila, W. (2011). Use and understanding of nutrition labels among consumers in Lilongwe (Malawi). African Journal of Food, Agriculture, Nutrition and Development, 11(5), 5171-5186.

Khare, A., Khare, A., \& Singh, S. (2012). Factors affecting credit card use in India. Asia Pacific Journal of Marketing and Logistics, 24(20), 236-256.

Mahgoub, S. E., Lesoli, P. P., \& Gobotswang, K. (2007). Awareness and Use of nutrition information on food packages among consumers in Maseru (Lesotho). African Journal of Food Agriculture Nutrition and Development, 7(6), 1-16.

Malhotra, N. K. (2009). Basic Marketing Research: A Decision-making approach (3rd ed.). New Jersey: Pearson.

Mannell, A., Brevard, P., Nayga Jr, R., \& Combris, P. (2006). French consumers' use of nutrition labels. Nutrition \& Food Science, 36(3), 159-168. http://dx.doi.org/10.1108/003346650610664896

Petrovici, D., Fearne, A., Nayga Jr, R. M., \& Drolias, D. (2012). Nutritional Knowledge, nutritional labels, and health claims on food: A study of supermarket shoppers in the South East of England. British Food Journal, 114(6), 768-783. http://dx.doi.org/10.1108/00070701211234318

Ranilovic, J., \& Baric, C. I. (2011). Differences between younger and older populations in nutrition label reading habits. British Food Journal, 113(1), 109-1212. http://dx.doi.org/10.1108/00070701111097376

Schiffman, L. G., \& Kanuk, L. L. (2007). Consumer Behavior (9th ed.). New Jersey: Pearson.

Shine, A., O’ Reilly, S., \& O’ Sullivan. (1997a). Consumer attitudes to nutrition labeling. British Food Journal, 99(8), 283-289.

Shine, A., O’ Reilly, S., \& O’ Sullivan. (1997b). Consumer use of nutrition labels. British Food Journal, 99(8), 290-296.

Siu, W., \& Tsoi, T. M. (1998). Nutrition label usage of Chinese consumers. British Food Journal, 100(1), 25-29. http://dx.doi.org/10.1108/00070709810202202

Subramaniam, R., \& Marimuthu, M. (2010). Bank credit card and the selection criteria: An exploratory study. African Journal of Business Management, 4(16), 3463-3472.

Wandel, M. (1997). Food labeling from a consumer perspective. British Food Journal, 99(6), 212-219.

Wiles, N. L., Paterson, M., \& Meaker, J. L. (2009). What factors determine the use of nutrition information on the food label when female consumers from Pietermaritzburg select 


\section{Macrothink}

Business and Management Horizons

ISSN 2326-0297 2013, Vol. 1, No. 1

and purchase fat spreads? South African Journal of Clinical Nutrition, 22(2), 69-73.

\section{Copyright Disclaimer}

Copyright reserved by the author(s).

This article is an open-access article distributed under the terms and conditions of the Creative Commons Attribution license (http://creativecommons.org/licenses/by/3.0/). 